\title{
Modeling the environmental impact of aquacultural facilities: a foundation for future management
}

\author{
DALE M. LICATA $\dagger$
}

Keywords: Aquaculture, modeling, environmental impact.

\begin{abstract}
A numerical model for computing the oxygen consumption and leakage of nutrients and organic matter from an aquacultural facility has been implemented. It is based upon the energy equation for fish and accounts for metabolism and growth over a range of temperatures and fish weight classes.

The model represents a promising management tool which can also assist aquaculturalists in determining optimal food rations. Furthermore, scientists, industrialists and pedagogues can use the model to facilitate and enhance their work. Sensitivity analysis indicates that additional studies examining protein, fat and carbohydrate assimilation rates are warranted. An alternative growth formulation could possibly improve results.
\end{abstract}

\section{Introduction}

The processes of birth, growth and death help characterize the life cycles of the fish or organisms harbored within an aquacultural facility. The system is a dynamic one with a given input registering a given response. An analogous description of the facility itself may also be drawn with the processes of facility establishment, expansion and shut down earmarking the different phases of the life cycle of an aquacultural facility.

As it now stands in Norway, facility establishment and expansion long outweigh facility shut down. Between 1974-1984 the production of salmon alone increased from 601 tons per year to a phenomenal 23,000 tons with production in 1987 anticipated to be 55,000 tons (Fishery Directorate, 1985). An assessment of the impact of this development has spurred investigations and evaluations of individual fjords as potential sites for aquacultural facilities.

Norway's acknowledgment of the biological and economic importance of its coastal waters, along with the realization that the coastal zone can succumb to the environmental pressures which the twentieth century is imposing, has led to the promotion of the philosophy that well constructed management schemes are a prerequisite to maintaining a productive, well-balanced ecosystem.

As time progresses so does the complexity of the situation. The posing of new legal questions, the dynamics of local and regional economics, the social and political forces at work and the environmental and engineering considerations that need to be made, make an inter-disciplinary team fundamental in attaining a solution. First the overall ecology of an area must be assessed. Then, by using the insight

Received 15 January 1987.

This paper was presented at the IFAC Symposium on Automation and Dataprocessing in Aquaculture, Trondheim, Norway, 18-20 August 1986.

This paper is reprinted with the permission of IFAC.

$\dagger$ Norwegian Hydrotechnical Laboratory (NHL), Klæbuveien 153, N7034 TrondheimNTH, Norway. 


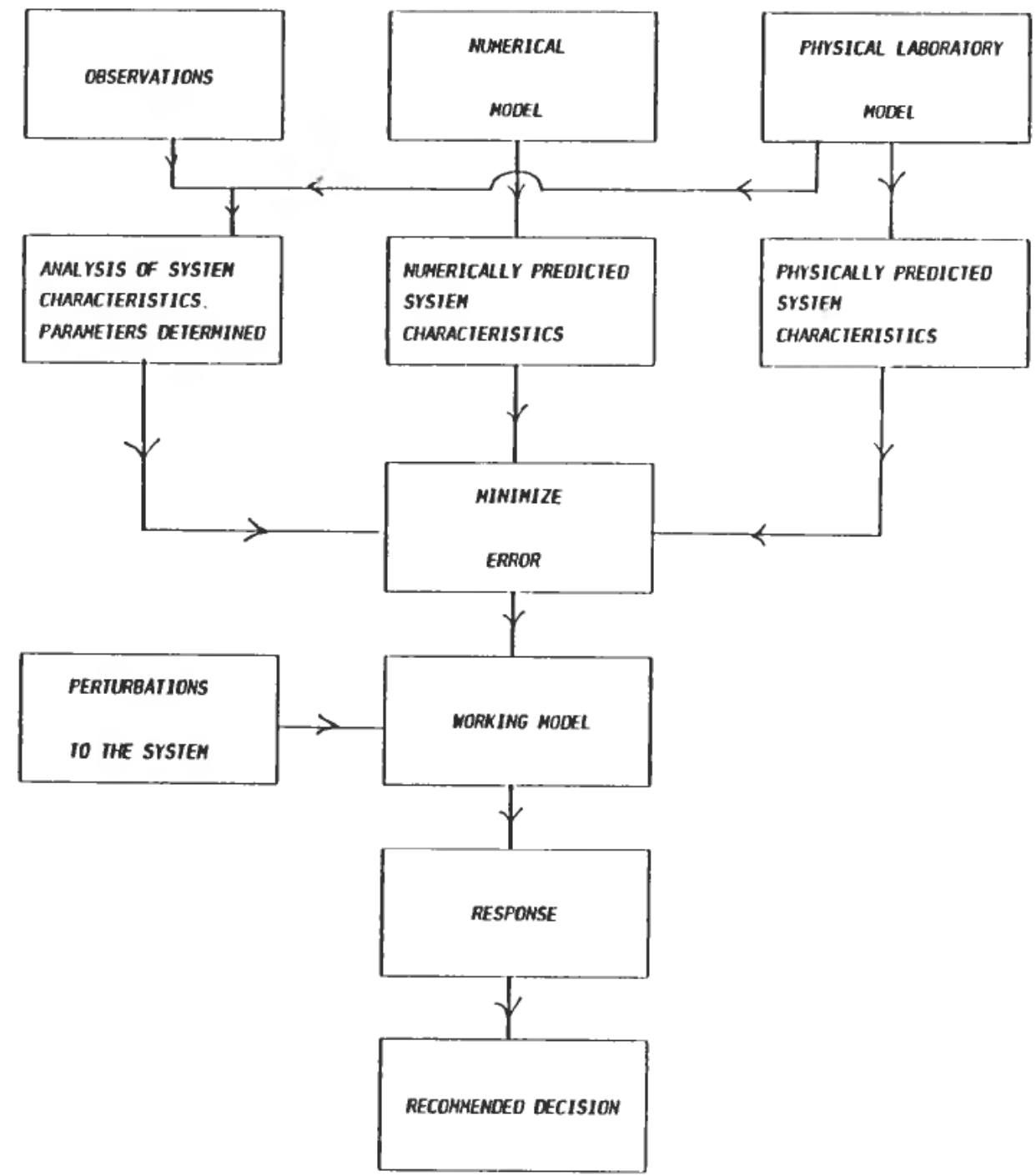

Figure 1. Schematic of oceanic descriptive/predictive system which can help in the management of aquacultural facilities.

gained from this assessment and from a comparison of the environmental, legal, economic, social and political implications of a given proposal, it is possible to develop a plan for future management of an area. It is hoped that such management can prevent a general deterioration of fjords and subsequently improve the quality of them without causing undue conflict between the alternative demands placed upon them.

One tactic for formulating these management alternatives involves developing a numerical model for the system. A fully developed model could include the interactions between aquacultural facilities, the environment (e.g. currents, waves, temperature, wind, icing, chemical and biological parameters), industry (various types of discharges and power stations) and alternative land use scenarios. By varying model variables and parameters, such a model could be used not only to evaluate various alternative strategies but would also provide a method for predicting events which could affect the system. 
Figure 1 illustrates one descriptive-predictive system which offers some possibilities as far as the planning of such a model is concerned. The interplay between physical laboratory models and measurements with model development is of prime importance. It allows the model to be verified, calibrated and modified according to ongoing developments. At the same time, physical models and field programs can be adjusted based on the results of the numerical model.

In this study a numerical model for computing the oxygen consumption and leakage of nutrients and organic matter from an aquacultural facility has now been implemented. It is based upon the theoretical formulation of Stigebrandt (1986). The results of this model will provide knowledge which is basic to the formulation of these management decisions. When the physical characteristics of the region (i.e. currents, temperature, salinity and wind conditions) are taken into account, this model can also help in dimensioning aquacultural facilities and in calculating the environmental impact of a facility. This paper discusses the theoretical foundation of the model and offers suggestions for applications and extensions of this work.

\section{Theoretical foundation}

\subsection{The energy equation for fish}

A convenient way to approach the modeling of an aquacultural system is to view it as a network composed of definitive compartments. Each compartment represents an environmental entity which undergoes a net flux. This net flux is defined as the difference between the rates of input and loss of some quantity (e.g. oxygen, biomass, nitrogen, energy, etc.)

Stigebrandt's model (1986) is based upon the energy equation for fish as given by Webb (1978). This equation may be written as follows:

where

$$
Q r-(Q f+Q n)=Q s+Q l+Q s d a+Q g+Q p
$$

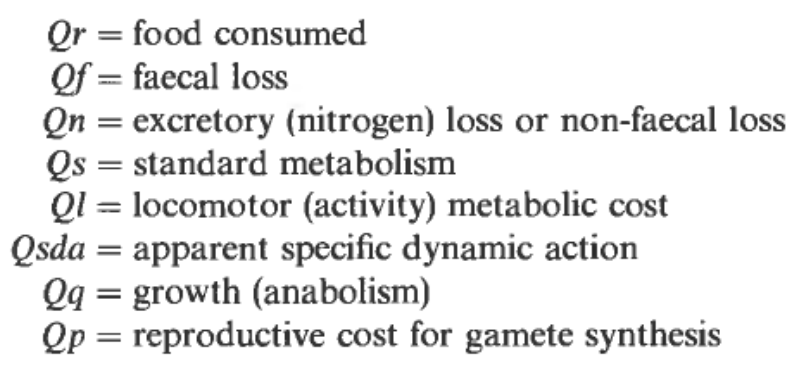

Figure 2 (Webb 1978) illustrates the distribution of energy (excluding reproduction) as expressed by this equation. As depicted, food ingested will be either assimilated or excreted. Of the energy assimilated a portion will be lost $(Q n)$ while the remainder is used for either metabolism (including locomotion and energy costs in connection with the digestion, assimilation and storage of food) or growth. The theoretical basis for this equation is described both by Webb (1978) and Stigebrandt (1986) and is reiterated here for the reader's convenience.

The total amount of energy available for fish will be directly related to the specific type of food available. The methodology adopted by Stigebrandt is based on a description of the amount of energy that a specific type of food will net. The food is essentially a conglomerate of protein, fat, carbohydrates, minerals and water. Each of the individual fractions will contribute a specific portion to the total energy with 


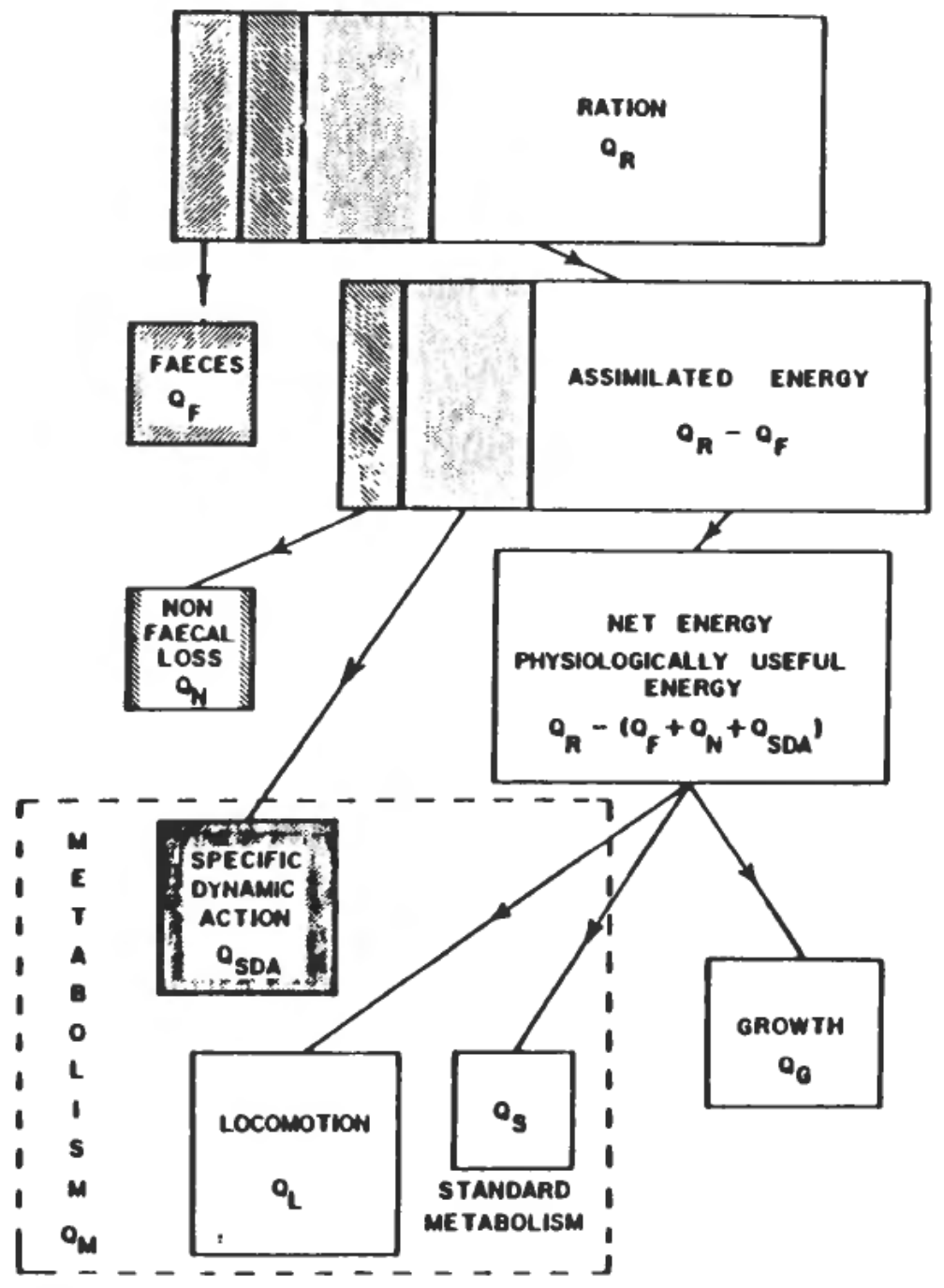

Figure 2. Flow diagram illustrating the consumption of energy by a fish. The size of each box illustrates likely proportions of energy loss or use by various components of the system under average conditions of food abundance and in the absence of stress. (Webb, 1978)

fats and carbohydrates contributing the largest and smallest proportion, respectively. By varying the protein, fat and carbohydrate content of food and total amount of energy available will change. Since protein, fat and carbohydrates are assimilated at different rates, the food composition will in turn affect the processes of excretion, metabolism, growth and reproduction. Consequently, the type of food used will have an impact not only on the production of the aquacultural facility but also on its potential environmental impact.

\subsection{Brief description of the different energy terms}

2.2.1. Qf: Faecal loss. Since proteins, fats and carbohydrates will be assimilated to different degrees, the faecal energy loss may be expressed as a function of the fraction of total energy consumed. Therefore the faecal loss is directly related to the type 
of food ingested. The author found no literature published on the extent to which each of these components is assimilated. Suggestions offered by Stigebrandt (personal communication, 1985) were used as a basis for the values adopted for use in this model. The choice of these values are discussed later in this paper.

2.2.2. Qn: Excretory (nitrogen) loss or non-faecal loss. Proteins which are assimilated in excess of growth requirements will be metabolized and subsequently excreted, mainly as ammonia. This results in an additional energy loss. In other words, if the food ingested has a protein content in excess of the metabolic requirements of the fish in the facility, the subsequent environmental impact will tend to increase. It is therefore important to accurately assess the metabolic requirements at any given stage of development and under any given set of environmental conditions so that the environmental impact can be minimized.

2.2.3. Qs: Standard metabolism. Metabolism in animals is, as discussed by Paloheimo and Dickie (1966), estimated using measurements of its oxygen consumption and body weight. In addition, at a particular level of food abundance and availability for a given temperature, fish adjust their metabolism and feeding to an essentially stable level (Paloheimo and Dickie, 1965)

The work of Winberg (1956) is useful in helping to estimate the metabolism for a given weight fish at a given temperature. He investigated the rate of resting metabolism for various species at various combinations of body size and temperature. In estimating the energy requirements for fish it is important to take into account the variation in metabolism with temperature and weight for the species being considered.

2.2.4. Qsda: Apparent specific dynamic action. Account needs to be taken of the higher metabolic level associated with searching for capturing, digesting and assimilating food. Mann (1978) cites two independent studies which showed that the metabolic rate of fish in nature is about twice that measured at a resting level. He also mentioned the work of Warren and Davis (1967) who suggested that the total metabolic rate of fish be determined by accounting for the increase in oxygen consumption associated with digestion, assimilation and storage of the food consumed. They called this activity Specific Dynamic Action, SDA, and suggested that its influence on metabolic rate would far outweigh that of swimming in search of food. This is probably a valid assumption for an aquacultural facility where feeding is controlled.

2.2.5. $Q g$ : Growth. Fish growth rates are related to the ration given, fish age/size and temperature. Typically fish will grow best at an optimum temperature and the growth rate will decrease as the temperature increases or decreases over/below this optimum. Investigations done by Brett, Shelbourn and Shoop (1969) showed that with increasing age, growth continues to slow down so that the optimum temperature becomes less apparent. The model implemented in this study does not account for this optimum. It assumes, rather, that the energy required for growth increases continuously as the size/weight of the fish increases. This will result in an over estimation of the energy requirements for growth as the fish achieves its maximum size.

\subsection{Abiotic effects}

Abiotic factors will influence the energy requirements of fish. Factors such as $\mathrm{pH}$, temperature and the presence of heavy metals will alter the energy requirements. In addition, stress due to overcrowding or lack of oxygen will play a role in 
determining the energy necessary for maintenance and growth. Changes in energy requirements result in more/less food being eaten thereby eventually affecting the potential environmental impact of any given site.

The most pronounced differences in the energy requirements of fish are those which arise from changes in temperature. Water temperature regulates the rate of all chemical and biological reactions occurring in the ecosystem. Based on the fact that biochemical rates in fish tend to double for every $10^{\circ} \mathrm{C}$ increase in temperature, the metabolic and growth rates determined are adjusted accordingly. In its current form, the model includes only the effects of temperature and not those of the other abiotic factors.

It should be noted that this model does not allow for a decrease in metabolism due to stress at higher temperatures. The rations calculated for temperatures above the optimum will therefore be greater than those actually required.

\subsection{Flow of matter in the system}

The objectives of modeling an aquacultural facility include both optimization of production and minimization of environmental loading. The concentration of phosphorus and nitrogen along with the oxygen content of the water may be used as indicators of environmental loading on the ecosystem.

2.4.1. Oxygen demands. The biological breakdown of the accumulated organic material from faeces and excess food will result in oxygen being depleted in the water column. As growth rates and survival rates of fish are dependent upon dissolved oxygen $(D O)$ concentrations, an examination of the potential oxygen demands on the system is warranted.

The major oxygen demands on the system include three sources:

(1) $\mathrm{DO} 2$ the respiration oxygen demand of the fish

(2) DOfe the oxygen required to breakdown the accumulating faeces

(3) DOfo the oxygen required to breakdown any food which is accumulating due to feeding beyond that which the fish will eat (hereafter referred to as excess food)

For these three sources, the oxygen demand will be dependent on the food composition. $D O 2$ will also depend on the current growth rate while $D O 2 f e$ will be markedly affected by the proportion of food that is assimilated. $D O 2 f o$ will increase as the food ration exceeds that which the fish will eat.

By examining the effect of food composition on the oxygen consumption of these three sources, a balance between overall production and the potential environmental impact may be achieved.

2.4.2. Ammonia excretion. Nitrogen, in its various forms $\left(\mathrm{NH}_{3}, \mathrm{NO}_{2}\right.$ and $\left.\mathrm{NO}_{3}\right)$ can deplete $D O$ levels in water, stimulate aquatic growth and prove toxic for aquatic life. It is therefore natural to follow the systematic cycling of micronutrients such as phosphorus and nitrogen in their various forms. By tracing and estimating their production and utilization along the existing pathways, any points of overproduction or depletion may be pinpointed.

The amount of ammonia excreted is dependent on the amount of food consumed and its composition. Once again, the necessity of accurately predicting metabolic and growth rates becomes apparent. 


\section{An example}

The theoretical model developed by Stigebrandt has been implemented on the Norsk Data 500 computer system. The model is written in an interactive format so that the user may supply parameter values directly from the computer terminal. The results from one run of the model are presented below in Tables 1-6.

\begin{tabular}{lrl}
\hline Average residual current velocity in the summer & $0 \cdot 10$ & $\mathrm{M} / \mathrm{S}$ \\
Standard deviation of the residual current & $0 \cdot 10$ & $\mathrm{M} / \mathrm{S}$ \\
Average tidal current velocity & $0 \cdot 10$ & $\mathrm{M} / \mathrm{S}$ \\
Highest expected summer temperature & $18 \cdot 00$ & $\mathrm{Deg} \mathrm{C}$ \\
Lowest expected winter temperature & $2 \cdot 00$ & $\mathrm{Deg} \mathrm{C}$ \\
Typical salinity at higher temperature & $30 \cdot 00$ & $\mathrm{ppt}$ \\
Average water depth under facility & $15 \cdot 00$ & $\mathrm{~m}$ \\
Depth of sill outside of facility & $10 \cdot 00$ & $\mathrm{~m}$ \\
Fjord area inside the sill & $1 \cdot 00$ & $\mathrm{sq} \mathrm{km}$ \\
Distance between sill and closest facility & $2 \cdot 50$ & $\mathrm{~km}$ \\
Typical wind velocity (summer) & $4 \cdot 00$ & $\mathrm{~m} / \mathrm{s}$ \\
\hline
\end{tabular}

Table 1. Physical data for the locale.

\begin{tabular}{lrl}
\hline Volume & 8000.00 & cu.m \\
Width perpendicular to current & 70.00 & $\mathrm{~m}$ \\
Depth of the nets & 5.00 & $\mathrm{~m}$ \\
Highest estimated fish density & 20.00 & $\mathrm{~kg} / \mathrm{cu} . \mathrm{m}$ \\
Minimum impact reduction factor from currents & 0.53 & \\
\hline
\end{tabular}

Table 2. Dimensions of the facility.

\begin{tabular}{lccc}
\hline & $\begin{array}{c}\text { Per cent by } \\
\text { mass }\end{array}$ & $\begin{array}{c}\text { Mean energy } \\
\text { content }\end{array}$ & $\begin{array}{c}\text { Fraction } \\
\text { assimilated }\end{array}$ \\
\hline Protein & 36.50 & $5650 \mathrm{cal} / \mathrm{g}$ & 0.97 \\
Fat & 16.50 & $9450 \mathrm{cal} / \mathrm{g}$ & 0.90 \\
Carbohydrate & 30.00 & $4100 \mathrm{cal} / \mathrm{g}$ & $0-60$ \\
\hline
\end{tabular}

Note: the percent by mass of the protein is Nitrogen $14 \cdot 7$

Phosphorus 2.3

Energy content of food: $3134 \cdot 00 \mathrm{cal} / \mathrm{gram}$

Table 3. Food characteristics.

\begin{tabular}{ccccc}
\hline $\begin{array}{c}\text { Temperature } \\
1{ }^{\circ} \mathrm{C}\end{array}$ & \multicolumn{4}{c}{$\begin{array}{c}\text { Weight } \\
\text { (kg) }\end{array}$} \\
\hline & 0.10 & 0.30 & 1.00 & 3.00 \\
4.0 & 0.92 & 0.67 & 0.48 & 0.35 \\
8.0 & 1.27 & 0.92 & 0.65 & 0.48 \\
12.0 & 1.75 & 1.27 & 0.90 & 0.66 \\
16.0 & 2.40 & 1.75 & 1.24 & 0.91 \\
20.0 & 3.31 & 2.41 & 1.71 & 1.26 \\
\hline
\end{tabular}

Table 4. Recommended feeding ( $\mathrm{kg}$ dry food/100 $\mathrm{kg}$ fish). 


\begin{tabular}{ccccc}
\hline $\begin{array}{c}\text { Temperature } \\
\left({ }^{\circ} \mathrm{C}\right)\end{array}$ & \multicolumn{2}{c}{$\begin{array}{c}\text { Nitrogen } \\
(\mathrm{kg} / \text { day) }\end{array}$} & (P.E.) & \multicolumn{2}{c}{$\begin{array}{c}\text { Phosphorus } \\
(\mathrm{kg} / \text { day) }\end{array}$} & (P.E.) \\
\hline 18 & $97 \cdot 9$ & 7832 & $15 \cdot 3$ & 6127 \\
10 & $51 \cdot 6$ & 4130 & $8 \cdot 1$ & 3231 \\
2 & $27 \cdot 2$ & 2177 & $4 \cdot 3$ & 1703 \\
\hline
\end{tabular}

* Assumes fish receive optimal food ration (Table 4)

Note: 1. Reduction in emission may be attained by decreasing the percent of protein in the food.

2. P.E. $=$ Person equivalent

Table 5. Emission of dissolved ammonia and phosphorus from the facility at highest (18) and lowest (2) temperature*.

\begin{tabular}{cccccrr}
\hline & & \multicolumn{5}{c}{ From excess food and excrement } \\
\cline { 3 - 7 } Overfeeding & Temp $\left({ }^{\circ} \mathrm{C}\right)$ & $\mathrm{kg} \mathrm{02/day}$ & $\mathrm{kg} \mathrm{N} /$ day & \multicolumn{1}{c}{ P.E. } & $\mathrm{kg} \mathrm{P} /$ day & P.E. \\
\hline 0 & 18 & $556 \cdot 19$ & $5 \cdot 15$ & 411.97 & $0 \cdot 81$ & $322 \cdot 29$ \\
25 & 18 & $1607 \cdot 99$ & $48 \cdot 06$ & $3845 \cdot 06$ & $7 \cdot 52$ & $3008 \cdot 04$ \\
50 & 18 & $2659 \cdot 78$ & $90 \cdot 98$ & $7278 \cdot 15$ & $14 \cdot 23$ & $5693 \cdot 79$ \\
0 & 10 & $293 \cdot 27$ & $2 \cdot 72$ & $217 \cdot 23$ & $0 \cdot 42$ & $169 \cdot 94$ \\
25 & 10 & $847 \cdot 88$ & $25 \cdot 34$ & $2027 \cdot 47$ & $3 \cdot 97$ & $1586 \cdot 12$ \\
50 & 10 & $1402 \cdot 48$ & $47 \cdot 97$ & $3837 \cdot 71$ & $7 \cdot 51$ & $3002 \cdot 29$ \\
0 & 2 & $154 \cdot 64$ & $1 \cdot 43$ & $114 \cdot 54$ & 0.22 & $89 \cdot 61$ \\
25 & 2 & $447 \cdot 08$ & $13 \cdot 36$ & $1069 \cdot 07$ & $2 \cdot 09$ & $836 \cdot 35$ \\
50 & 2 & $739 \cdot 52$ & $25 \cdot 29$ & $2023 \cdot 60$ & 3.96 & $1583 \cdot 09$ \\
\hline
\end{tabular}

Table 6. Latent oxygen demand $(U O D)$, nitrogen and phosphorus at various temperatures for different degrees of overfeeding (if feeding is as prescribed in Table 4 then overfeeding is $0 \%$.

Tables 1 and 2 present the physical data for the locale and the dimensions of the facility. This information is supplied by the user. Table 3 first summarizes the assumptions made regarding the food characteristics and the fraction assimilated for the various components and then calculates the energy content of the food. Table 4 presents the recommended feeding for different size fish at various temperatures based on eqn. 13. The expected values for dissolved ammonia and phosphorus emitted are given in Table 5. Table 6 accounts for the latent oxygen demand and the nitrogen and phosphorus inputs resulting from the buildup of excess food and excrement. The process of denitrification is not taken into account here.

\section{Sensitivity analysis}

In a study such as this, the most useful and reliable information that may be gained is the sensitivity of the solution to the value of uncertain parameters. To derive predictions based on the results of a single model run would be presumptuous. 
To evaluate the effect of protein, fat and carbohydrate assimilation rates on the model results, five additional runs were performed:

\begin{tabular}{cccc} 
Run & \multicolumn{2}{c}{ Fraction assimilated } & \\
Protein & Fat & Carbohydrate \\
Original & 97 & 90 & 60 \\
1 & 90 & 90 & 60 \\
2 & 85 & 90 & 60 \\
3 & 90 & 85 & 60 \\
4 & 85 & 85 & 60 \\
5 & 90 & 90 & 40
\end{tabular}

Reducing the amount of carbohydrates and fat assimilated while maintaining a constant level of protein assimilation results in a slight increase in ammonia and phosphorus emissions (Table 5). (For example: comparison of cases 1 and 3 shows a $2.5 \%$ increase for a $5.5 \%$ decrease in fat assimilation; cases 1 and 5 : a $33 \%$ decrease in carbohydrate assimilation results in an $8 \%$ increase). A reduction in the protein assimilation rate reduced the ammonia and phosphorus concentration. (For example, original case to case 2 : a $12 \%$ decrease in protein assimilation resulted in a $22 \%$ decrease in ammonia and phosphorus.)

Comparisons between the resulting alternatives for Table 6 revealed that decreasing assimilation rates increased latent oxygen demand $(U O D)$. The effect was most pronounced for protein with a $12 \%$ change in rate causing a $40 \%$ increase in $U \mathrm{OD}$ at $0 \%$ overfeeding. What was unexpected was the fact that in all cases, the percentage increase in $U O D$ decreased at higher levels of overfeeding. For example, from $40 \%$ to $7 \%$ at $50 \%$ overfeeding. Further work is needed to examine the effect of not having included denitrification in these calculations.

Though nitrogen and phosphorus loading from excess food and excrement (Table 6) increased slightly with decreasing fat and carbohydrate assimilation rates, the most dramatic changes occurred when the protein assimilation rate was decreased. A $12 \%$ decrease in the assimilation rate resulted in nitrogen and phosphorus values which at $0 \%$ overfeeding were four times greater. At $50 \%$ overfeeding the increases were less dramatic: $21 \%$.

Though time limitations precluded it for now, future work will evaluate the sensitivity of the model to other expressions for the variation in biological reactions with temperature. Another possibility is to express the variation as a function of the length of fish as opposed to weight.

\section{Calibration and verification}

The parameter or input uncertainty in numerical models limits the accuracy of the results to nothing better than the accuracy of the input used to generate it. The parameters of special interest in this model include the assimilation rates of protein, fat and carbohydrates, the variation of metabolic and growth rates with temperature and stress levels and excretion rates relative to protein intake. While there is uncertainty about the proper value to be used in any particular problem, a reasonable value may be assigned through field experiments, theoretical considerations and past experience.

To calibrate and establish confidence in the predictive ability of the model it is necessary to compare the predictions with observations and experimental results. 
Perfect agreement between the two is precluded because of the difficulty in obtaining completely reliable field and laboratory measurements as well as the complexity of the processes being predicted. Model comparisons to field and experimental studies should be evaluated not as an attempt to achieve a perfect fit, but rather as an effort to obtain an indication of the model's ability to reproduce certain key features of the data, such as the variation in growth rate at different temperatures and feeding levels. After the parameters are adjusted so that model results approximate observations to within acceptable limits, the model must be verified. This is done by comparing model predictions with additional sets of data.

The values used in this study have been adopted from the work of Stigebrandt. It is hoped that continued work on this model will reveal that accuracies and inaccuracies which result from doing so. Meanwhile, work needs to be continued on several fronts.

Additional studies relating food consumption, growth rate and metabolic rate at various temperature and stress levels are fundamentally important. Energy budgets can be more accurately determined when the measures of the efficiency and food conversion and energy loss through metabolism and excretion are clearly established. By determining the effect that ration level and temperature have on the different body constituents, the model can be extended to finding the feeding scheme that gives the desired water, protein and fat combination in fish.

Estimating growth rates by interpreting the scale features of fish in a manner analogous to using rings of trees has been explored for carp (Eknath and Doyle, 1985). Doing so for salmonids could provide the model with improved growth criteria as well as providing the basis for breeding program design. Recently, Jensen (1985) derived equations expressing the dependence of maximum growth on temperatures below the optimal for Brown trout and Arctic char. He suggested that the growth potential for Atlantic salmon would be higher. Determining how much higher as well as examining changes in this potential at temperatures over the optimum would help in improving the representation of growth processes in the model.

Investigations regarding the dependence of the efficiency of food conversion on food composition would provide a stronger foundation for the model. Studies indicate (Kaushik and Teles, 1985) that food and protein utilization are higher in trout fed on gelatinized starch than those fed on a diet containing raw starch. Furthermore, nitrogen excretion in trout fed on gelatinized starch is lower. Additional studies such as this for various species might help to establish the food composition which results in the highest utilization and maximum growth rates. This could in turn be used in verifying the model.

Feeding frequency and diet have been shown to have a significant impact on the chronic effects of gas supersaturation (Colt, Orwicz and Brook, 1985). Providing a two-way link between numerical model results and laboratory experiments will provide insight into the extent of such effects for salmonids. Finding a feeding frequency/diet that minimizes the effect of supersaturated discharges would alleviate some of the conflicts arising between aquaculturalists and hydropower plant developers.

Interest has been growing for using artificially induced circulation to maintain a more constant temperature in the aquacultural facility and ensure a supply of fresh oxygen rich water. At the same time, concern has been expressed over the potential for promoting planktonic productivity due to the concomitant increase in micro- 
nutrients which follows when deeper water is brought up towards the surface. The work of Costa-Pierce and Laws (1985) indicates that in freshwater prawn aquaculture ponds that chlorophyll A concentrations and primary production rates and production indices were not significantly different under stratified and well-mixed conditions. With the use of artificially induced circulation being examined as a viable alternative for increasing water renewal in fjords where circulation is restricted by the presence of a sill, it would be advisable to investigate this phenomenon for conditions typical for Norwegian fjords. This would help in establishing a firmer basis for representing such processes in a numerical model.

The concerns over the buildup of ammonia in the area surrounding an aquacultural facility might be assuaged if a method for removing this by-product was found. Since bacterial nitrification results in efficient removal of ammonia from water perhaps the use of a 'bacterial bed' beneath a facility would provide a solution. A solution might be found by including such a system as a component in a numerical model while simultaneously performing laboratory experiments.

\section{Potential applications and extensions}

The primary purpose of this particular computer modeling effort has been one of prediction: quantitative prediction of the behaviour of the aquatic system in which an aquacultural facility is the sole contributing source of 'pollution'. As presented in this paper, this model is a tool which may be used by the aquaculturalist, the environmentalist and the scientist. It enables the aquaculturalist to estimate the feeding requirements for a given type of food under a given set of temperature conditions. The environmentalist can examine the environmental loading incurred for alternative food compositions while the biotechnologist examines changes in feeding requirements. For the scientist a model such as this will help in guiding sampling programs and in identifying the areas which warrant further research. The most promising applications of this model become manifest when it is coupled with other numerical models.

For example, when combined with a hydrodynamic model which includes current, wave, wind and temperature/icing condition, the scope of application of this model widens. The circulation brought by wind, currents and waves plays a major role in transporting pollution away from any given area as well as renewing the oxygen supply. The ultimate determination of the highest ammonia and lowest oxygen concentrations which might be expected from any given facility will therefore be dependent on this circulation. If the results of combining this circulation with the results of the model described in this paper indicate that oxygen concentrations approach levels detrimental to the fish population (e.g. $<5 \mathrm{mg} / \mathrm{l}$ ), or that ammonia concentrations increase to unacceptable levels (e.g. $>0.5 \mathrm{mg} / \mathrm{l}$ ), then a redimensioning of the facility must be considered.

Additional justification for the coupling of this model with a hydrodynamic model is the fact that hydrodynamic conditions need to be taken into consideration when estimating the build-up of a sediment mound of faeces/excess food beneath the facility. Knowing how the currents affect the sedimentation from a given facility will enable an estimation of the production which ultimately causes oxygen consumption in the bottom water to become an imminent problem. This will provide additional data for estimating the carrying capacity of the facility. Estimating the proper 
carrying capacity will insure against overloading which places the fish under stress thereby lowering the production potential of the facility.

For the aquaculturalist who is striving to optimize the size of his/her facility and must also consider the potential environmental loading which will follow, the use of a numerical model is ideal. In the long term a balance must be attained between production and environmental effects. The coupling of an economic model with the model previously described will help in achieving this balance. Though this model is foreseen as being applied directly to a sea based facility it may be modified for one which is land based. Alternative production scenerios can be examined if recirculation and water treatment are incorporated into the model.

An extension of the model which examines the possibility of artificially inducing/ enhancing currents in an area would also be desirable. A reduction in the environmental loading and a stimulation of production in the facility may be ensured if consideration is given both to the natural circulation around the facility and the location of the facility. A numerical model would facilitate the determination of the optimal position of such a propeller.

The effect of changes in the current/wave characteristics induced by man-made structures such as road fillings and floating bridges may also be evaluated by using a model which incorporates both circulation and environmental loading. The growing demand on the road network along the western coast of Norway necessitates such a predictive capability if conflicts of interest between aquaculturalists and road authorities are to be minimized.

Another possibility is to incorporate a model which describes the periodic planktonic blooms which occur along the Norwegian coast. An examination of the relationship between an aquacultural facility and toxic blooms will be facilitated. Measures for potentially minimizing the effects of such blooms can be assessed.

When coupled with industrial models (for example, industrial discharges, both thermal and chemical, and hydroelectric power stations) additional applications of this model become apparent. Conflicts often arise between the industrialist and the aquaculturalist which need to be quantified so that the actual impact on the aquacultural facility can be more readily assessed. A model which incorporates aspects of both industry and aquaculture will facilitate such an assessment and help in finding a solution that can minimize or totally avoid the conflict. Furthermore, attention can be drawn to conflicts which otherwise might have arisen unexpectedly. For example, the discharge of water from hydroelectric power stations which is supersaturated with dissolved gas causes concern among aquaculturalists because of the potentially lethal gas bubble disease which ensues when fish are exposed to such waters (Berg, McClimans, Rye, Telde and Watne, 1984). A numerical model could help in assessing the extent of such supersaturation, the effects on the aquacultural facility and alternative discharge scenarios which when implemented contribute to resolving the conflict.

For the coastal zone planner/manager a fully coupled model offers a myriad of possibilities. The effects of various resource allocation schemes may be evaluated from a more quantitative point of view and the carrying capacity of the system may be determined. The environmental and economic consequences of various engineering projects can be more completely evaluated by interpreting and examining the results of the model which integrates physical, chemical, biological and economic components of the system. In addition, the effectiveness of control policies specifically designed to hinder/reverse eutrophication in an area may be assessed. A fully 
integrated model will help in identifying the environmental factors to which the system is most sensitive. This will in turn enable an assessment of the recoverability of the system to changes in a particular variable. In addition, better insight into long-term effects will be obtained.

The success of future coastal zone planning/management schemes depends on the awareness and understanding of today's students to the system's inherent characteristics, problems and interactions. Incorporating an integrated model into a resource management "game" will allow students to get a "feel" for the behaviour of the system being studied. The appeal of computerization will allow students to apply their analytical skills to the decision making process for a resource system in which economic and political factors as well as biological factors must be considered while actually enjoying themselves.

\section{Conclusions}

The development and implementation of a numerical model for the environmental loading produced by an aquacultural facility represents the first step in developing a tool which may eventually be applied to the management of such a facility. The usefulness of this model extends over disciplinary boundaries and provides a link between various interest groups. The age of the computer has provided the capability of solving problems and answering questions in an efficient and stimulating manner.

Just as the revolutionary development within the realm of the micro-chip continues and produces a new generation computer, so too will this model undergo continual modification. As research and model results provide a better understanding of the dynamics of the system the model will need to be updated. Doing so will ensure that management schemes for aquacultural facilities, and for our coastal resources in general, rest firmly on a stable foundation.

There are several limitations with the model as it now stands. For the first, the growth formulation is based on the assumption that the fish are not subjected to stress caused, for example, by sudden/prolonged periods of temperature extremes or overcrowding. As stress conditions can significantly alter the behaviour and biological response of fish, an assessment of the effect of stress on the model results should be made. The current model formulation does not completely predict the effect of temperature on metabolic and growth rates. Account should be made for the fact that fish exhibit a temperature optimum. That is to say that metabolism and growth do not continually increase with temperature but rather increase up to the optimum and then decrease. With increasing age, though, growth slows down and this optimum tends to become less apparent (Brett, Shelboum and Shoop, 1969). The increase in growth and food consumption rates with increasing oxygen concentration should be accounted for when examining the effect of the discharge of supersaturated water from a hydroelectric power plant.

Because the major pathways in the cycling of inorganic micronutrients (nitrogen and phosphorus) include the presence of both phytoplankton and zooplankton, a more complete representation of the cycling of these nutrients must include these vital links. The effects of this will be most pronounced when considering planktonic blooms. Dissolved organic phosphorus is often estimated from dissolved organic $\mathrm{N}$ using the elemental ratio $16: 1$, the ratio most commonly used for $\mathrm{N}: \mathrm{P}$ ratios of 
organic matter in marine ecosystems (Redfield, Ketchum and Richards, 1963). The model needs to be evaluated to see if the results conform to this ratio.

Finally, it should be remembered that a model such as this should not be used as an absolute prediction mechanism for the environmental impact of an aquacultural facility. Rather, it should be used as a tool to test the sensitivity of the system to changes in the facility size, feeding schemes, food composition, currents, water exchange conditions, nutrient loading or other modifications that might be considered within the framework of a management scheme. From an engineering perspective this model provides a means of prediction and therefore a possibility to alter the design of the system. In doing so viable management schemes can be formulated. It was for this purpose that this model was implemented.

\section{ACKNOWLEDGMENTS}

This work would not have been possible had it not been for the openness of Anders Stigebrandt in sharing his preliminary results, both the theoretical and numerical. A sincere thanks is therefore directed to him both in this regard and for graciously answering my questions along the way. I would also like to extend my thanks to NHL's librarian, Trine Klingenberg, for so quickly obtaining all the publications used as a basis for this work. Funding for this project was provided by SINTEF.

\section{REFERENCES}

Berg, A., McClimans, T., Rye, H., Tekle, T., and Watne, M. (1984). Superstaturation of dissolved air in the waterways of hydroelectric power plants - causal relationships, detrimental effects and preventative measures. NHL report STF60 A84075, $98 \mathrm{pp}$.

Brett, J. R., Shelbourn, J. E., and ShOOP, C. T. (1969). Growth rate and body composition of fingerling sockeye salmon, Oncorhynchus nerka, in relation to temperature and ration size. J. Fish. Res. Bd. Canada, 26, 2363-2394.

Colt, J., ORwiCz, K., and BrooKs, D. (1985). The effect of gas supersaturation on the growth of juvenile channel catfish, Ictalurus punctatus. Aquaculture, 50, 153-160.

Costa-Pierce, B. A., and LAws, E. A. (1985). Effects of destratification on autotrophic and heterotrophic microplanktonton productivity in eutrophic aquaculture ponds. Aquaculture, 50, 141-151.

EknATH, A. E., and Doyle, R. W. (1985). Maximum likelihood estimation of 'unobservable' growth and development rates using scale data: application to carp aquaculture in India. Aquaculture, 49, 55-71.

Fishery Directorate (1985). Resource overview for 1985 and the status of aquaculture as of 1985. Fisken og Havet, No. 1. Report from the Fishery Directory, Dept. of Water Research: Bergen (In Norwegian). 84 pp.

JENSEN, W. (1985). The potential growth of salmonids. Aquaculture, 48, 223-231.

Kaushik, S. J., and Ourvia Teles, A. (1985). Effect of digestible energy on nitrogen and energy balance in rainbow trout. Aquaculture, 50, 89-103.

ManN, K. H. (1978). Estimating the food consumption of fish in nature. In S. D. Gerking (Ed.). Ecology of Freshwater Fish Production, (Blackwell Scientific Publications, Oxford), pp. 250-273.

Paloheimo, J. E. and Dickie, L. M. (1965). Food and Growth of Fishes I: A Growth Curve Derived from Experimental Data. Fish. Res. Bd. Canada 22(2), pp. 521-542

Redfield, A. C., Ketchum, B. H., and Richards, F. A. (1963). The influence of organisms on the composition of sea water. In M. N. Hill (Ed.). The Sea, Vol. 2. (Wiley Interscience, New York), pp. 26-77.

STIGEBRANDT, A. (1986). Model calculations of an aquacultural facility's environmental impact, NIVA report: 0-86004, 28 pp. (In Swedish). 
WARREN, C. E. and DAVIS, G. E. (1967). Laboratory studies on the feeding bioenergetics and growth of fish. In: The Biological Basics of Freshwater Fish Production, Gerking, S. D. (Editor), (Blackwell Scientific Publications, Oxford), pp. 175-214.

WebB, P. W. (1978). Partitioning of energy into metabolism and growth. In S. D. Gerking (Ed.). Ecology of Freshwater Fish Production (Blackwell Scientific Publications, Oxford), pp. 184-214.

WiNBERG, G. G. (1956). Rate of metabolism and food requirements of fish. Fish Res. Bd. Can. Transl. Ser. 194, 1960, pp. 1-253 